\title{
Early response to furosemide as a kidney injury predictor and peritoneal dialysis in post cardiac surgical patients: a case-controls study
}

\begin{abstract}
Introduction: The objective of this study is to evaluate the early use of furosemide with the development of kidney injury and the need for peritoneal dialysis in patients who were submitted to cardiac surgeries. Our hypothesis suggests that diuresis initiated 2 hours after the first dose of furosemide relates to kidney injury and the start of peritoneal dialysis in a patient in whom cardiac surgery was performed.
\end{abstract}

Material and methods: A case-control study from October 1st, 2016 to August 31 st, 2018 in the Pediatric Intensive Care Unit (PICU) of the University Hospital in Monterrey, Mexico. Inclusion criteria: ages 0 to 18years old and postcardiac congenital surgery; exclusion criteria were acute or chronic kidney injury prior to surgery, dialysis performed before surgery and congenital kidney pathology.

Results: 67 patients were included, furosemide was used in 49 of them, 13 patients received peritoneal dialysis and 36 did not. An early response to furosemide with the development of kidney injury was found with a diuresis $(2.1 \mathrm{~mL} / \mathrm{kg} / \mathrm{hour}[ \pm 2.57])$ after 2 hours of furosemide at a dose of $1 \mathrm{mg} / \mathrm{kg} /$ hour $[ \pm 0.45]$ and a $\mathrm{p}$ value of 0.001 .The statistical analysis of the need for peritoneal dialysis and early response to furosemide (3.28 $[ \pm 2.51]$ vs $2.0[ \pm 2.60] \mathrm{mL} / \mathrm{kg} /$ hour) has a $\mathrm{p}$ value of 0.051 .

Discussion and/or conclusion: The early response to furosemide in post cardiac surgical pediatric patients can predict the presence of an acute kindey injury however it does not predict the need for peritoneal dialysis.

Keywords: pediatric intensive care unit, patient, peritoneal dialysis, exclusion criteria, inclusion criteria

\author{
Volume 8 Issue 6 - 2018
}

\author{
Arturo Gerardo Garza-Alatorre, ' Veronica \\ Rodriguez-Martinez,' Aaron Rodriguez- \\ Sanchez, ${ }^{2}$ Deborah Lizeth Nuñez-Elizondo, ${ }^{3}$ \\ Jesus Torres-Guevara ${ }^{3}$ \\ 'Professor of the Pediatric Critical Care Medicine Unit of the \\ University Hospital “Dr. Jose Eleuterio Gonzalez", Mexico \\ ${ }^{2}$ Second year resident of Pediatric Critical Care Medicine of the \\ University Hospital “Dr. Jose Eleuterio Gonzalez", Mexico \\ ${ }^{3}$ Medicine Students, Facultad de Medicina, Universidad \\ Autónoma de Nuevo Leon, Mexico
}

Correspondence: Arturo Gerardo Garza-Alatorre, Professor of the Pediatric Critical Care Medicine Unit of the University Hospital “Dr. Jose Eleuterio Gonzalez”, Mexico, Email agavza2004@gmail.com

Received: October 18, 2018 | Published: November 16, 2018

\section{Introduction}

Acute kidney injury in post cardiac surgical patients is still considered a high mortality cause in this population. It is most important to identify kidney injury in these patients from the beginning, being a decisive factor for treatment. However, many of the kidney injury classifications are focused on creatinine clearance and serum levels so they are considered late markers for its identification.

The early use of kidney replacement has proven to be an important component in order to modify mortality, intensive care stay, decrease in fluid overload, days of mechanical ventilation and time spent in hospital.

The objective of this study was to evaluate the early use of furosemide with the development of kidney injury and the need for peritoneal dialysis in post cardiac surgical patients. Our hypothesis suggests that diuresis initiated 2 hours after the first dose of furosemide relates to the stage of kidney injury and the start of peritoneal dialysis in a patient in whom cardiac surgery was performed.

\section{Materials and methods}

Case control study performed from October $1^{\text {st }}, 2016$ to August $31^{\text {st }}, 2018$ in the Pediatric Intensive Care Unit (PICU) of the University Hospital "Dr. Jose Eleuterio Gonzalez" in Monterrey, Mexico. Inclusion criteria were: ages 0 to 18 years old and post cardiac congenital surgery; exclusion criteria were acute or chronic kidney injury prior to surgery, dialysis performed before surgery and congenital kidney pathology.

Acute kidney injury was classified according to the Kidney Disease Improving Global Outcome 2016. "Early response to furosemide" was defined as the first dose of furosemide initiated in the first 24hours upon arrival in the PICU, measuring dose in $\mathrm{mg} / \mathrm{kg} /$ dose and measurement of diuresis $(\mathrm{mL} / \mathrm{kg} / \mathrm{dose})$ in the first 2 hours after medication was started.

The demographic variables and the early response variables in both groups will be expressed in mean and standard deviation. After documenting the normal distribution through the KolmogorovSmirnov Test and proving the equality in variances with the Levene Test, the T-student and ANOVA or the U Mann-Whitney and KruskalWallis Test will be used depending on the case. A value of $p<0,05$ was considered to have statistical significance. The entire statistical analysis was performed with the program SPPS v.18 for Windows $10 .^{1-6}$

\section{Results}

A total of 74 surgeries were considered however seven patients were excluded ( 6 incomplete files and 1 patient with kidney injury prior to surgery). Furosemide was used during the first 24hours post operation in 49 patients, in which 13 received peritoneal dialysis and 36 did not. 
Patients who did not receive dialysis were older $(766[ \pm 1,492]$ vs $77[ \pm 114]$ days $)$ and weighed more $(9.8[ \pm 14.4]$ vs $3.72[ \pm 1.33] \mathrm{kg})$. The association of early response to furosemide with the development of kidney injury was studied and a diuresis upon 2 hours $(2.1 \mathrm{~mL} / \mathrm{kg}$ hour $[ \pm 2.57])$ of the furosemide dose $(1 \mathrm{mg} / \mathrm{kg} /$ hour $[ \pm 0.45])$ presented a statistical significance with a $\mathrm{p}$ value of 0.001 . When performing the statistical analysis regarding the association between the need for peritoneal dialysis and early response to furosemide $(3.28[ \pm 2.51]$ vs $2.0[ \pm 2.60] \mathrm{mL} / \mathrm{kg} /$ hour $)$ there was no statistical significance observed, finding a p value of 0.051 (Figure 1) ( Table $1,2 \& 3$ ).

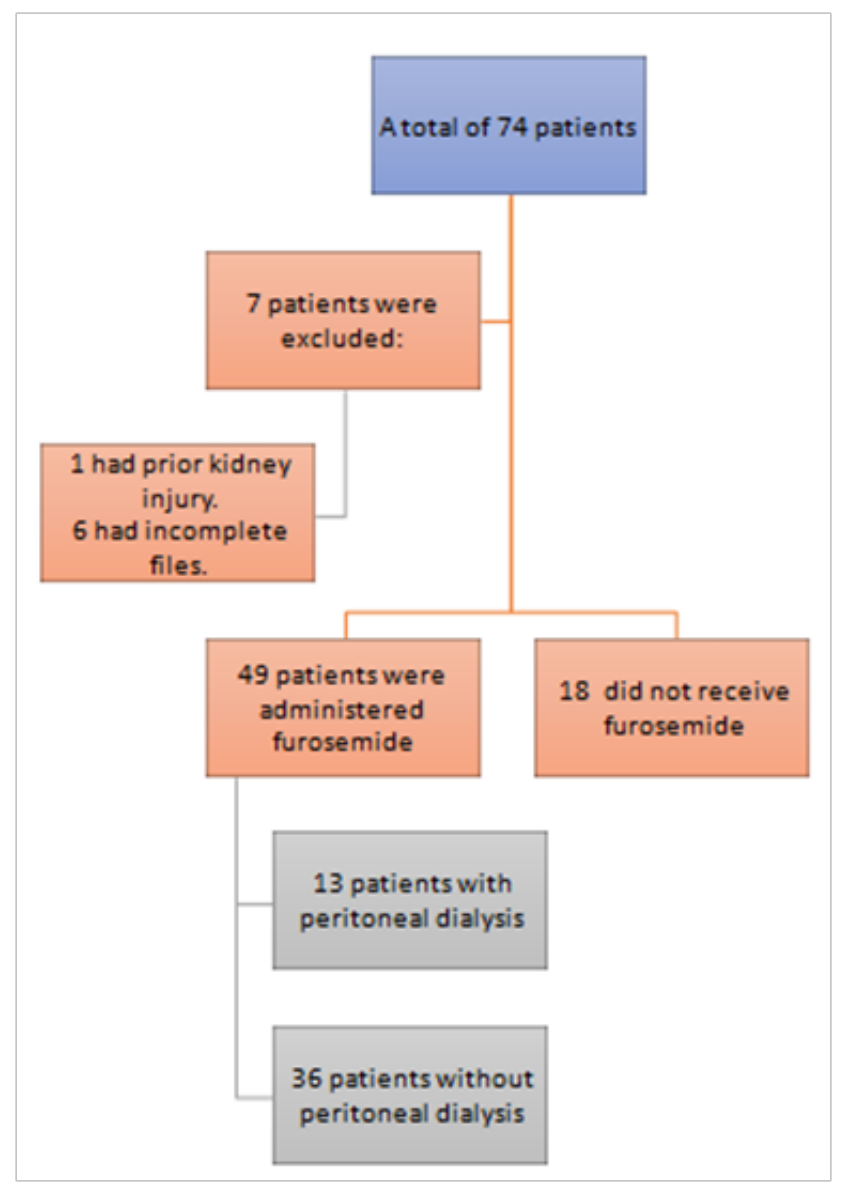

Figure I Flow chart of patient distribution.

Table I Clinical characteristics of patients postoperated from cardiac surgery who were included in the early response protocol with furosemide

\begin{tabular}{lll}
\hline & Without peritoneal dialysis $\mathbf{N}=\mathbf{3 6}$ & With peritoneal dialysis $\mathbf{N}=\mathbf{1 3}$ \\
\hline Age (Days) & $766( \pm 1,492)$ & $77( \pm 114)$ \\
Gender & & $6(46.15 \%)$ \\
Male & $21(58.33 \%)$ & $7(53.85 \%)$ \\
Female & $15(41.67 \%)$ & $3.72( \pm 1.33)$ \\
Weight $(\mathrm{Kg})$ & $9.8( \pm 14.4)$ & $0.23( \pm 0.05)$ \\
Total body surface & $0.40( \pm 0.37)$ & \\
Nutritional status & & $6(46.15 \%)$ \\
Eutrophic & $23(63.88 \%)$ & $7(53.84 \%)$ \\
Malnutrition & $13(36.11 \%)$ & 0 \\
Overweight-Obese & 0 & \\
\hline
\end{tabular}


Table 2 Relation of early response to furosemide with kidney injury

\begin{tabular}{lll}
\hline & Total patients $\mathbf{N}=\mathbf{4 9}$ & $\boldsymbol{p}$ \\
\hline Furosemide dose (mg/kg/hour) & $1( \pm 0.45)$ & \\
Diuresis at 2hours (mL/kg/hour) & $2.1( \pm 2.57)$ & 0.001 \\
Acute kidney injury & \\
Stage I & $12(24.48 \%)$ \\
Stage II & $6(12.24 \%)$ & \\
Stage III & $17(34.69 \%)$ \\
No injury & $14(28.57 \%)$ & \\
\hline
\end{tabular}

Table 3 Early response to furosemide related with kidney injury

\begin{tabular}{lll}
\hline & Without peritoneal dialysis $\mathbf{N}=\mathbf{3 6}$ & With peritoneal dialysis $\mathbf{N}=\mathbf{1 3}$ \\
\hline Dose of furosemide $(\mathrm{mg} / \mathrm{kg} /$ hour $)$. & $0.84( \pm 0.44)$ & $1.08( \pm 0.44)$ \\
Diuresis at 2hours $(\mathrm{mL} / \mathrm{kg} /$ hour $)$. & $3.28( \pm 2.51)^{*}$ & $2.0( \pm 2.60)^{*}$ \\
Deaths & &
\end{tabular}

$* \mathrm{p}=0.051$

\section{Discussion and/or conclusion}

A direct association between the development of kidney injury and an early response in the pediatric postcardic surgical patients was found; this was proven previously by Kakajiwala et al. ${ }^{7}$

In our study, there was no relation between the early response to furosemide and the need for peritoneal dialysis. The criteria for the initiation of peritoneal dialysis was based on the judgment of the patient's physician as well as on the few criteria established for the start of dialysis in this population. It is necessary to perform other studies to rule out the relation between those and define the indications for starting kidney replacement therapy.

In conclusion, the early response to furosemide in pediatric post cardiac surgical patients may predict the presence of acute kidney injury however not the need for initiating peritoneal dialysis. ${ }^{8-14}$

\section{Acknowledgements}

None.

\section{Conflict of interest}

The author declares no conflict of interest

\section{References}

1. Wyckoff T, John GT. Advances in acute kidney injury associated with cardiac surgery: the unfolding revolution in early detection. $J$ Cardiothorac Vasc Anesth. 2012;26(2):340-345.

2. Lee SH, Kim S-J, Kim HJ, et al. acute kidney injury following cardiopulmonary bypass in children-- risk factors and outcomes. Circ J. 2017;81(10):1522-1527.

3. Ostermann M, Joannidis M. Acute kidney injury 2016: diagnosis and diagnostic workup. Crit Care. 2016;20(1):299.

4. Toda Y, Sugimoto K. AKI after pediatric cardiac surgery for congenital heart diseases-recent developments in diagnostic criteria and early diagnosis by biomarkers. J Intensive Care. 2017;5:49.
5. Ortega-Loubon C, Fernandez-Molina M, Carrascal-Hinojal Y, et al. Cardiac surgery-associated acute kidney injury. Ann Card Anaesth. 2016;19(4):687-698.

6. Akcan-Arikan A, Gebhard DJ, Arnold MA, et al. Fluid overload and kidney injury score: a multidimensional real-time assessment of renal disease burden in the critically Ill Patient. Pediatr Crit Care Med. 2017;18(6):524-530.

7. Kakajiwala A, Kim JY, Hughes JZ, et al. Lack of furosemide responsiveness predicts acute kidney injury in infants after cardiac surgery. Ann Thorac Surg. 2017;104(4):1388-1394.

8. Cooper DS, Basu RK, Price JF, et al. The Kidney in Critical Cardiac Disease: Proceedings From the $10^{\text {th }}$ International Conference of the Pediatric Cardiac Intensive Care Society. World J Pediatr Congenit Heart Surg. 2016;7(2):152-163

9. Cooper DS, Kwiatkowski DM, Goldstein SL, Krawczeski CD. Acute kidney injury and cardiorenal syndromes in pediatric cardiac intensive care. Pediatr Crit Care. 2016;17(8 Suppl 1):S250-256.

10. Greenberg JH, Zappitelli M, Devarajan P, et al. Kidney outcomes 5years after pediatric cardiac surgery: The TRIBE-AKI study. JAMA Pediatr. 2016;170(11):1071-1078.

11. Karim HM, Yunus M, Saikia MK, Kalita JP, Mandal M. Incidence and progression of cardiac surgery-associated acute kidney injury and its relationship with bypass and cross clamp time. Ann Card Anaesth. 2017;20(1):22-27.

12. Calderón-Colmenero J, Ramírez-Marroquín S, Cervantes-Salazar J. Métodos de estratificación de riesgo en la cirugía de cardiopatías congénitas. Archivos de Cardiología de México. 2008;78(1)60-67.

13. Tamburro RF, Thomas NJ, Ceneviva GD, et al. A prospective assessment of the effect of aminophylline therapy on urine output and inflammation in critically ill children. Front Pediatr. 2014;2:59.

14. Ryo Matsuura, Komaru Y, Miyamoto Y, et al. Response to different furosemide doses predicts AKI progression in ICU patients with elevated plasma NGAL levels. Ann Intensive Care. 2018;8(1):8. 